\title{
Deberes de los altos cargos andaluces en ejercicio
}

\author{
José María Pérez Monguió \\ Profesor de Derecho Administrativo \\ Universidad de Cádiz
}

\begin{abstract}
SUMARIO: I. OBJETO Y SISTEMÁTICA DE ESTUDIO.- II. DEDICACIÓN EXCLUSIVA Y RETRIBUCIÓN ÚNICA- III. INCOMPATIBILIDADES DE LOS ALTOS CARGOS. 1. Deber de declaración de las posibles causas de incompatibilidad.- 2. Causas de incompatibilidad.- 3. Consecuencias jurídicas de la falta de compatibilidad.- IV. ACTIVIDADES COMPATIBLES. 1. Actividades privadas compatibles. a) Administración del patrimonio personal o familiar. b) Producción y creación literaria, artística, científica y técnica. c) Colaboración y participación en congresos, seminarios, conferencias, jornadas. d) Participación en actividades de instituciones culturales o benéficas. 2. Actividades públicas compatibles.- V. RÉGIMEN DEL DEBER DE DECLARACIÓN DE ACTIVIDADES, BIENES E INTERESES.- 1. Deber de declaración de los altos cargos.- 2. La obligación de informar a los altos cargos de sus obligaciones en materia de incompatibilidad.- 3. Contenido de las declaraciones de actividades, bienes e intereses.- 4 . Formas y plazo de presentación de las declaraciones.- 5. La transparencia de las declaraciones: la publicidad.- 6. Consecuencias jurídicas de la falta de presentación de las declaraciones.- 7. La especialidad de las declaraciones tributarias.- Bibliografía
\end{abstract}

\section{RESUMEN:}

En este trabajo se realiza un análisis del régimen actual de los altos cargos en Andalucía, concretamente, de los deberes que asumen con la designación y que tienen que respetar y cumplir durante el tiempo del ejercicio del cargo. De esta forma se abordan el deber de dedicación exclusiva y de retribución única, las causas de incompatibilidad y de compatibilidad y, por último, la configuración del deber de declaración de actividades, bienes e intereses.

Palabras clave:

Altos cargos, dedicación exclusiva, retribución única, incompatibilidad, actividades privadas compatibles, declaración de actividades, bienes e interés.

\section{ABSTRACT}

The aim of this paper is to analyze the top political positions within the current adminstation in Andalucia, specifically of the assumed duties inherent in the 
designated position, which must be adhred to and fulfilled throoughout the time in office. Areas this paper deals with are the duty to exclusive dedication to the office and single source of income, the reasons for compatibility and incompatibility.

Keyword

Top political positions, exclusive dedication, the reasons for compatibility and incompatibility.

\section{OBJETO Y SISTEMÁTICA DE ESTUDIO}

En los últimos años han sido diversos los escándalos que han salpicado a los altos cargos en España, con independencia de la Administración y el color del partido al que pertenecen ${ }^{1}$. Esta situación, unida a la crisis económica, ha potenciado un debate social que exige un replanteamiento de las normas existentes, tanto estatales como autonómicas, con el fin último de potenciar los instrumentos precisos para garantizar la independencia, la imparcialidad y la eficacia en el ejercicio de sus funciones.

Estas demandas sociales van más allá, y exigen, como expone la exposición de la Ley Foral 2/2011, de 17 de marzo, por el que se establece un código de buen gobierno, «que los poderes e instituciones públicas, ofrezcan a los ciudadanos el compromiso de que todos sus representantes en el ejercicio de sus funciones han de cumplir no solo las obligaciones previstas en las leyes, sino que, además, su actuación ha de inspirarse y guiarse por principios éticos y de conducta que hasta ahora no han sido plasmados expresamente en las normas, aunque sí se inducían de ellas y que conforman un código de buen gobierno».

En Andalucía se aprecia igualmente esta inquietud por la materia que se refleja en distintas iniciativas actuales tanto del Gobierno como de los grupos par-

${ }^{1}$ El catorce de septiembre de 2011, el Tribunal Supremo revocó la Sentencia del Tribunal Superior de Justicia de Andalucía, Sevilla (Sala de lo Contencioso-Administrativo, Sección 1ª), de 13 enero 2011 (RFCA 2011 211) que exigía a la Junta de Andalucía abrir expediente a Manuel Chaves, ex presidente de la Junta, por el caso Matsa por una supuesta infracción de la ley de incompatibilidades de altos cargos al no inhibirse en el procedimiento de concesión de un incentivo millonario a favor de la empresa Minas de Aguas Teñidas MATSA en la que su hija era apoderada. Véase, sobre este particular, http://www.elmundo.es/elmundo/2011/09/14/espana/1315997773.html; http://www.cadenaser.com/espana/articulo/supremo-anula-expediente-sancionador-chaves-caso-matsa/csrcsrpor/20110914csrcsrnac_3/Tes; http://www.larazon.es/noticia/8921-el-supremo-impide-que-se-investigue-chaves-por-el-caso-matsa; http://www.elcorreoweb.es/andalucia/130201/ts/revoca/decision/tsja/abrir/expediente/chaves/caso/matsa 
lamentarios ${ }^{2}$, todo ello con independencia de la sensibilidad de la Comunidad Autónoma desde los años ochenta, cuando se dotó de la primera ley de altos cargos en 1984, a través de la Ley 5/1984, de 23 de abril ${ }^{3}$ y en el año 2005, se aprobó la ley de segunda generación, es decir, la Ley 3/2005, de 8 de abril, de incompatibilidades de altos cargos de la Administración de la Junta de Andalucía y de declaración de actividades, bienes e intereses de altos cargos y otros cargos públicos, desarrollada por el Decreto 176/2005, de 26 de julio, de Incompatibilidades de altos cargos de la Administración de la Junta de Andalucía y de declaración de actividades, bienes e intereses de altos cargos y otros cargos públicos ${ }^{4}$.

Ante este escenario, donde la sociedad está muy interesada por la materia, donde el Gobierno apunta medidas para profundizar en la transparencia y democracia y donde los Grupos Parlamentarios han presentado proposiciones de ley para la modificación la Ley $3 / 2005$, de 8 de abril, parece oportuno realizar un análisis del régimen actual de los altos cargos en Andalucía, concretamente, del concerniente a los deberes que asumen con la designación y que tienen que cumplir durante el tiempo del ejercicio del cargo con el fin de detectar las posibles incoherencias y lagunas, y formular, en su caso, las propuestas de lege ferenda oportunas.

De este manera dejaremos al margen el estudio del régimen sancionador o la situación de los altos cargos tras el cese para centrarnos en los deberes de dedicación exclusiva y la retribución única, en las causas de incompatibilidad y de compatibilidad y, por último, abordaremos el deber de declaración de actividades, bienes e intereses.

\footnotetext{
${ }^{2}$ Entre estas acciones se encuentra el papel destacado de la materia entre las 27 medidas presentadas por el Presidente de la Comunidad de Autónoma de Andalucía en el Debate del Estado de la Comunidad de 2011, concretamente en la medida 25, que se encuadra en el epígrafe, Más transparencia y democracia, proponía suprimir cualquier tipo de privilegio en materia de pensiones que pueda tener atribuido cualquier cargo público en Andalucía». En el Boletín Oficial del Parlamento de Andalucía se han publicado dos proposiciones de ley, una del Grupo Parlamentario Socialista (8-11/PPL-000008) y otra del Grupo Parlamentario Popular (8-11/PPL-000010). Esta segunda recibió el criterio contrario Consejo Gobierno a la toma en consideración (BOPA núm. 739/2011, de 9 de septiembre).

${ }^{3}$ La Ley 6/1983, de 21 de julio, del Gobierno y Administración solamente regulaba las incompatibilidades del Presidente y de los Consejeros sin detenerse en el régimen de los altos cargos.

${ }^{4}$ Este decreto desarrollaría, entre otros, aspectos las actividades incompatibles y exceptuadas, la declaración de posibles causas de incompatibilidad, las actividades, bienes e intereses, el contenido de la declaración, el plazo de presentación, la dependencia y publicidad del Registro, la información y obligación de declarar, el examen, subsanación e inscripción de las declaraciones, la potestad sancionadora, las actuaciones previas, el procedimiento sancionador y los órganos
} 


\section{DEDICACIÓN EXCLUSIVA}

Los altos cargos, en virtud de la especial actividad que desarrollan, están sujetos a un régimen de dedicación absoluta y exclusiva y de esta circunstancia se deriva el régimen estricto de incompatibilidades que tendremos la ocasión de analizar en las siguientes páginas. De este modo, el artículo 3.1 de la Ley Andalucía 3/2005, reproduciendo el artículo 1.1 de la Ley Andalucía 5/1984, dispone que el ejercicio de un alto cargo será «incompatible con el desarrollo por sí o mediante sustitución de cualquier otro cargo, profesión o actividad, públicos o privados, por cuenta propia o ajena, retribuidos mediante sueldo, arancel, participación o cualquier otra forma especial, incluida la docencia y los cargos electivos de representación popular en colegios, cámaras o entidades que tengan atribuidas funciones públicas».

Por tanto, podemos afirmar que la regla general es la incompatibilidad de toda actividad pública o privada ajena al cargo, pese a la existencia de excepciones ${ }^{5}$, y todo ello en aras de preservar el principio de eficacia y a la vez de imparcialidad en el desarrollo de su función; garantizando, en la medida de lo posible, que la actuación del mismo sea totalmente independiente a cualquier tipo de intereses ajenos al puesto desempeñado ${ }^{6}$.

competentes, la prescripción de infracciones y sanciones y la obligatoriedad de comunicación de los nombramientos; todo ello, según el preámbulo, «con objeto de asegurar la dedicación y la eficacia, la moralización de la vida pública y la ejemplaridad y transparencia que el ejercicio de estas altas funciones conlleva». Este Decreto fue modificado por el Decreto 231/2005, de 25 octubre, con objeto de añadir un segundo párrafo al artículo 5 del Decreto 176/2005, de 26 de julio, por el que se desarrolla la Ley $3 / 2005$, de 8 de abril, de Incompatibilidades de Altos Cargos de la Administración de la Junta de Andalucía y de Declaración de Actividades, Bienes e Intereses de Altos Cargos y otros Cargos Públicos, dando lugar a la redacción siguiente: «Respecto a lo previsto en el artículo 8.5 de la Ley 3/2005, deberán ingresarse en la Tesorería de la Comunidad Autónoma las cantidades que se perciban correspondientes a las pensiones causadas por los Altos Cargos incluidos en el artículo 2.1 de dicha Ley».

${ }^{5}$ Véanse los artículos 4, 5 y 6.d) y f) de la Ley Andalucía 3/2005 y 4 del Decreto Andalucía $176 / 2005$.

${ }^{6}$ Así la exposición de motivos de la Ley Andalucía 3/2005 resalta como uno de los argumentos para la aprobación de este texto normativo se halla en la conveniencia de «regular de modo más estricto el régimen de incompatibilidades de los citados cargos a fin de reforzar su independencia, imparcialidad y dedicación exclusiva a los asuntos públicos, evitando cualquier interferencia en los intereses públicos de otros intereses». Esta es una idea que se repite en las distintas leyes que regulan el ejercicio de los altos cargos. De esta manera resulta muy clarificadora la exposición de motivos de la Ley Foral 2/2011, de 17 de marzo, por el que se establece un código de buen gobierno que cuando manifiesta que: «Desde la entrada en vigor de la Constitución Española, y del Amejoramiento del Fuero, el ordenamiento jurídico se ha enriquecido con diversas normas que confor- 
Junto con el régimen de dedicación exclusiva y absoluta, la Ley Andalucía 3/2005 establece el principio de incompatibilidad económica o de retribución única que les impide percibir más de una remuneración con cargo a los presupuestos de las Administraciones Públicas, ni de los organismos, entidades y empresas de ellos dependientes o con cargo a los órganos constitucionales - art. $3.3^{-7}$.

Este régimen tiene sus excepciones en las actividades privadas compatibles pero en el caso de actividades públicas compatibles, la cuestión es diversa. Así, en los supuestos en que los altos cargos ostenten las condición de parlamentario, formen parte de órganos colegiados o de otra naturaleza de las Administraciones Públicas cuando les corresponda con carácter institucional o para los que fuesen designados en función del cargo, representen a la Administración de la Junta de Andalucía en órganos de gobierno o consejos de administración de empresas con capital público o participen en actividades en instituciones culturales o benéficas anejas al cargo, las empresas u organismos tienen la obligación de ingresar directamente en la Tesorería de la Comunidad Autónoma las cantidades que se devenguen, incluidas las indemnizaciones por asistencia -arts. 3.3 y 4.3 de la Ley Andalucía 3/2005 y art. 5 Decreto Andalucía 176/2005-.

Del mismo modo se procederá en los supuestos de participación de los altos cargos en toda clase de actividades en instituciones culturales y /o benéficas anejas al cargo.

\section{INCOMPATIBILIDADES DE LOS ALTOS CARGOS}

\section{Deber de declaración de las posibles causas de incompati- bilidad}

La Ley Andalucía 3/2005 establece la obligación de los altos cargos de declarar sobre las causas de posibles incompatibilidades con el ejercicio del car-

man el marco en el que han de actuar los miembros del Gobierno, los altos cargos de las Administraciones Públicas, los funcionarios públicos y el resto del personal de las Administraciones Públicas, incluidos los representantes de las instituciones forales, para ejercer sus funciones de acuerdo al bloque de la legalidad, que garantiza la transparencia, eficacia y dedicación plena a sus funciones públicas y evita toda aquella actividad o interés que pudiera comprometer su independencia e imparcialidad o menoscabar el desempeño de sus deberes públicos».

${ }^{7}$ Véanse, entre otros, el artículo 4 Ley 13/2005, de 27 de diciembre, del régimen de incompatibilidades de los altos cargos al servicio de la Generalidad o el artículo 8 Ley de Cantabria 1/2008, de 2 de julio, reguladora de los Conflictos de Intereses de los miembros del Gobierno y de los altos cargos de la Administración de Cantabria. 
go en el plazo que se establezca reglamentariamente -art. 10-8 ${ }^{8}$, correspondiendo resolver al titular de la Consejería de Hacienda y Administración Pública -artículo 7.1 del Decreto 176/2005-9. ${ }^{9}$. En este sentido, la regulación resulta enormemente pobre y carece de la agilidad necesaria para detectar las posibles incompatibilidades pues, como mínimo, el alto cargo estará dos meses en esta situación de incompatibilidad sin que fuese detectado por la Administración. Por este motivo, entendemos que la fórmula empleada por la normativa andaluza no es operativa. Para intentar solventar esta situación proponemos de lege ferenda que fuese obligatorio, por parte de los altos cargos, presentar una comunicación, previa al nombramiento, de las posibles causas de incompatibilidad pues, a diferencia de las declaraciones de actividades, bienes e intereses que responden a un principio de transparencia y de publicidad sin que afecten a la eficacia o imparcialidad, las declaraciones de incompatibilidad pueden tener efectos sobre el propio nombramiento como veremos más adelante y, por ello, no resulta razonable que se establezca el mismo plazo para la presentación de una y otra. Sólo de esta manera, el futuro alto cargo podría adecuar su situación al régimen de incompatibilidades sin incurrir en ninguna infracción de las contempladas en la Ley en la medida que aún no habría sido designado.

\section{Causas de incompatibilidad}

Los altos cargos son incompatibles entre sí y en particular, como dispone el artículo 6 de la Ley Andalucía 3/2005, con:

- Todo otro cargo que figure al servicio o en los presupuestos de las administraciones, organismos o empresas públicas, o con cualquier actividad por cuenta directa o indirecta de las mismas, así como las funciones públicas retribuidas mediante arancel, participación o cualquier otra forma especial.

- El desempeño por sí o por persona interpuesta de cargos de todo orden, funciones de dirección o de representación, así como de asesoramiento y mediación de empresas o sociedades concesionarias, empresas inmobilia-

${ }^{8}$ Plazo que se fijó en dos meses desde la fecha del nombramiento (art. 7.2 Decreto Andalucía 176/2005).

${ }^{9}$ El Decreto del Presidente 14/2010, de 22 de marzo, sobre reestructuración de Consejerías ha suprimido la Consejería de Justicia y Administración Pública, surgiendo las Consejerías de Gobernación y Justicia y de Hacienda y Administración Pública. En este nuevo esquema, la referencia del artículo 7.1 del Decreto 176/2005 debe entenderse realizada a la Consejería de Hacienda y Administración Pública. 
rias, contratistas de obras, servicios o suministros, o con participación o ayudas del sector público, cualquiera que sea la configuración jurídica de aquéllas, con la excepción prevista en el artículo 5 de la Ley 3/2005.

- El ejercicio de cargos, por sí o por persona interpuesta, que lleven anejas funciones de dirección, representación o asesoramiento de toda clase de compañías, sociedades mercantiles y civiles, y consorcios de fin lucrativo, aunque unas y otros no realicen fines o servicios públicos ni tengan relaciones contractuales con las administraciones, organismos o empresas públicas.

- El ejercicio por sí o por persona interpuesta o mediante sustitución de la profesión a la que por razón de sus títulos o aptitudes pudiera dedicarse, salvo que se trate de actividades culturales o científicas efectuadas de forma no continuada.

- La percepción de pensiones de derechos pasivos o de cualquier régimen de Seguridad Social público y obligatorio.

- El ejercicio de toda clase de actividades en instituciones culturales o benéficas, salvo autorización del órgano que los nombró o que fueran anejas al cargo.

- La gestión, defensa, dirección o asesoramiento de asuntos particulares ajenos, cuando por la índole de las operaciones de los asuntos competa a las Administraciones Públicas resolverlos o quede implicado en ellos la realización de algún fin o servicio público.

- Figurar en cualquier forma de promoción de empresas o actividades profesionales privadas.

- El ejercicio de funciones de dirección en cámaras, colegios profesionales, sindicatos y organizaciones empresariales.

\section{Consecuencias jurídicas de la falta de compatibilidad}

El hecho de incurrir en incompatibilidad, entendemos tras la apreciación por el titular de la Consejería de Hacienda y Administración Pública -art. 7 Decreto 176/2005-, puede tener consecuencias diversas en virtud de la causa en la que se incurra, como podemos apreciar en el siguiente cuadro, todo ello sin perjuicio de las infracciones en las que se podrían haber incurrido por este motivo. 
Consecuencias de la falta de compatibilidad

\begin{tabular}{|c|c|}
\hline Incompatibilidad & Consecuencias \\
\hline $\begin{array}{l}\text { Con todo cargo que figure al servicio o en los presupues- } \\
\text { tos de las administraciones, organismos o empresas pú- } \\
\text { blicas, o con cualquier actividad por cuenta directa o in- } \\
\text { directa de las mismas, así como las funciones públicas re- } \\
\text { tribuidas mediante arancel, participación o cualquier } \\
\text { otra forma especial. }\end{array}$ & $\begin{array}{l}\text { Pase a la situación administrativa que } \\
\text { en cada caso proceda. }\end{array}$ \\
\hline $\begin{array}{l}\text { Con el desempeño por sí o por persona interpuesta de } \\
\text { cargos de todo orden, funciones de dirección o de repre- } \\
\text { sentación, así como de asesoramiento y mediación de } \\
\text { empresas o sociedades concesionarias, empresas inmobi- } \\
\text { liarias, contratistas de obras, servicios o suministros, o } \\
\text { con participación o ayudas del sector público cualquiera } \\
\text { que sea la configuración jurídica de aquéllas con la ex- } \\
\text { cepción de las actividades derivadas de la mera adminis- } \\
\text { tración del patrimonio personal o familiar, salvo en el su- } \\
\text { puesto de participación superior al } 10 \% \text { entre el titular } \\
\text { del alto cargo, su cónyuge, pareja de hecho inscrita en el } \\
\text { correspondiente registro, hijos menores y personas tute- } \\
\text { ladas en el capital de sociedades que tengan conciertos, } \\
\text { contratos o concesiones de cualquier naturaleza con el } \\
\text { sector público estatal, autonómico o local. }\end{array}$ & $\begin{array}{l}\text { Suspensión en el ejercicio de los cargos. } \\
\text { Prohibición de obtenerlos mientras ejer- } \\
\text { zan los que son causa de incompatibilidad } \\
\text { y durante dos años después de su cese. } \\
\text { Excepciones: } \\
\text { Cuando fueren designados para los } \\
\text { mismos en representación de las } \\
\text { Administraciones Públicas. } \\
\text { Cuando los estuvieren ejerciendo y hu- } \\
\text { bieren cesado por razón de su } \\
\text { nombramiento. }\end{array}$ \\
\hline $\begin{array}{l}\text { Con el ejercicio de cargos, por sí o por persona inter- } \\
\text { puesta, que lleven anejas funciones de dirección, repre- } \\
\text { sentación o asesoramiento de toda clase de compañías, } \\
\text { sociedades mercantiles y civiles, y consorcios de fin lu- } \\
\text { crativo, aunque unas y otros no realicen fines o servicios } \\
\text { públicos ni tengan relaciones contractuales con las admi- } \\
\text { nistraciones, organismos o empresas públicas. }\end{array}$ & $\begin{array}{l}\text { Suspenderán también toda actuación o } \\
\text { actividad propia de los cargos compren- } \\
\text { didos en el mismo, por todo el tiempo } \\
\text { que sirvan los que dan causa a la in- } \\
\text { compatibilidad, durante cuyo término } \\
\text { de servicio tampoco podrán obtener } \\
\text { nuevos cargos; si bien al cesar en aqué- } \\
\text { llos podrán reintegrarse al ejercicio de } \\
\text { éstos, sin restricción alguna de plazo. }\end{array}$ \\
\hline $\begin{array}{l}\text { Con el ejercicio por sí o por persona interpuesta o me- } \\
\text { diante sustitución de la profesión a la que por razón de } \\
\text { sus títulos o aptitudes pudiera dedicarse, salvo que se tra- } \\
\text { te de actividades culturales o científicas efectuadas de for- } \\
\text { ma no continuada. }\end{array}$ & $\begin{array}{l}\text { Cese en el ejercicio profesional activo } \\
\text { mediante sustitución, mientras sirvan el } \\
\text { cargo. }\end{array}$ \\
\hline $\begin{array}{l}\text { Con la percepción de pensiones de derechos pasivos o de } \\
\text { cualquier régimen de Seguridad Social público y obliga- } \\
\text { torio. }\end{array}$ & $\begin{array}{l}\text { Las pensiones que se perciban, se ingre- } \\
\text { sarán en la Tesorería de la Comunidad } \\
\text { Autónoma. }\end{array}$ \\
\hline $\begin{array}{l}\text { Con la gestión, defensa, dirección o asesoramiento de } \\
\text { asuntos particulares ajenos, cuando por la índole de las } \\
\text { operaciones de los asuntos competa a las Administracio- } \\
\text { nes Públicas resolverlos o quede implicado en ellos la re- } \\
\text { alización de algún fin o servicio público. }\end{array}$ & $\begin{array}{l}\text { Prohibición de las actividades referidas } \\
\text { durante el ejercicio del cargo y hasta dos } \\
\text { años después de su cese, en lo que com- } \\
\text { pete a la Administración de la Junta de } \\
\text { Andalucía. }\end{array}$ \\
\hline
\end{tabular}




\section{ACTIVIDADES COMPATIBLES}

\section{Actividades privadas compatibles}

La Ley Andalucía 3/2005 no contiene ningún precepto específico dedicado a la compatibilidad del cargo público con las actividades privadas, como es el caso de Cantabria ${ }^{10}$, Cataluña ${ }^{11}$, La Rioja ${ }^{12}$ o Galicia $^{13}$, entre otras, o de la propia Ley estatal ${ }^{14}$. Únicamente contempla un precepto -art. 5- que recoge el régimen de la compatibilidad con la administración del patrimonio personal o familiar y el resto se encuentran en el artículo dedicado al régimen general de incompatibilidades, prohibiendo la compatibilidad y después estableciendo una excepción. El Decreto Andalucía 176/2005, en el artículo 4, bajo la rúbrica Actividades exceptuadas, recoge las actividades excluidas del régimen de dedicación absoluta y exclusiva, entre las que se encuentran las públicas, en el apartado primero, y las privadas en el segundo.

Las actividades privadas compatibles son, en general, las mismas que en el resto de Comunidades Autónomas, salvo en materia de docencia universitaria que queda fuera del régimen de incompatibilidad, como veremos en los siguientes epígrafes.

La falta de sistemática del precepto produce una ausencia de armonía en el texto. Pero aún es más relevante es el hecho de que se permita la compatibilidad sin limitación alguna en los supuestos contemplados. Es decir no queda condicionada la compatibilidad de la actividad al hecho de que no se comprometa la imparcialidad o independencia ${ }^{15}$ o a que suponga un menoscabo

${ }^{10}$ Art. 11 Ley de Cantabria 1/2008, de 2 de julio, reguladora de los Conflictos de Intereses de los miembros del Gobierno y de los altos cargos de la Administración de Cantabria.

${ }^{11}$ Art. 8 Ley 13/2005, de 27 de diciembre, del régimen de incompatibilidades de los altos cargos al servicio de la Generalidad.

12 Art. 56 Ley 8/2003, de 28 de octubre, del Gobierno e Incompatibilidades de sus miembros de la Comunidad Autónoma de la Rioja.

${ }^{13}$ Art. 7 Ley 9/1996, de 18 de octubre, de incompatibilidades de los miembros de la Junta de Galicia y altos cargos de la administración autonómica.

${ }^{14}$ Art. 10 Ley 5/2006, de 10 de abril, de regulación de los conflictos de intereses de los miembros del Gobierno y de los Altos Cargos de la Administración General del Estado.

${ }^{15}$ Véanse, entre otros, los artículos 11 Ley de Cantabria 1/2008, de 2 de julio, reguladora de los Conflictos de Intereses de los miembros del Gobierno y de los altos cargos de la Administración de Cantabria; 7 Ley 2/1996, de 19 de noviembre, de incompatibilidades de los miembros del Gobierno y de los altos cargos de la Comunidad Autónoma de las Islas Baleares; 7 Ley 
al ejercicio del cargo ${ }^{16}$ pese a que pudiera, de alguna manera y haciéndose una interpretación finalista, entenderse que va implícito.

\section{Actividades privadas compatibles}

\begin{tabular}{|c|c|c|}
\hline Regla general & Excepción & Artículos \\
\hline $\begin{array}{l}\text { Las actividades deriva- } \\
\text { das de la mera adminis- } \\
\text { tración del patrimonio } \\
\text { personal o familiar. }\end{array}$ & $\begin{array}{l}\text { Participación superior al diez por } \\
\text { ciento entre el titular del alto cargo, } \\
\text { su cónyuge, pareja de hecho inscrita } \\
\text { en el correspondiente Registro, hijos } \\
\text { menores y personas tuteladas en el } \\
\text { capital de sociedades que tengan } \\
\text { conciertos, contratos o concesiones } \\
\text { de cualquier naturaleza con el sector } \\
\text { público estatal, autonómico o local. }\end{array}$ & Art. 5 Ley 3/2005 \\
\hline \multirow{2}{*}{$\begin{array}{l}\text { Es incompatible la condición } \\
\text { de alto cargo: } \\
\text { Con el ejercicio por sí o } \\
\text { por persona interpuesta } \\
\text { o mediante sustitución } \\
\text { de la profesión a la que } \\
\text { por razón de sus títulos o } \\
\text { aptitudes pudiera dedi- } \\
\text { carse, salvo que se trate } \\
\text { de actividades culturales } \\
\text { o científicas efectuadas } \\
\text { de forma no continuada. }\end{array}$} & $\begin{array}{l}\text { La producción y creación literaria, } \\
\text { artística, científica y técnica, así co- } \\
\text { mo las publicaciones derivadas de } \\
\text { aquéllas que podrán efectuarse de } \\
\text { forma no habitual y siempre que no } \\
\text { sean consecuencia de una relación } \\
\text { de empleo o prestación de servicios. }\end{array}$ & $\begin{array}{l}\text { Art. 6.d) Ley } 3 / 2005 \\
\begin{array}{c}\text { Art. 4.2.a) Decreto } \\
\text { 176/2005 }\end{array}\end{array}$ \\
\hline & $\begin{array}{l}\text { La colaboración y participación en } \\
\text { congresos, seminarios, conferencias, } \\
\text { jornadas, coloquios o cursos siempre } \\
\text { que tengan carácter esporádico y } \\
\text { ocasional y no estén financiados es- } \\
\text { pecíficamente por la Administración } \\
\text { de la Junta de Andalucía. }\end{array}$ & $\begin{array}{c}\text { Art. } 6 . d) \text { Ley } 3 / 2005 \\
\text { Art. } 4.2 . b) \text { Decreto } \\
\text { 176/2005 }\end{array}$ \\
\hline
\end{tabular}

9/1996, de 18 de octubre, de incompatibilidades de los miembros de la Junta de Galicia y altos cargos de la administración autonómica y 8.2 Ley 3/1997, de 8 de mayo, de incompatibilidades de los miembros del Gobierno y Altos Cargos de la Administración Pública de la Comunidad Autónoma de Canarias.

${ }^{16}$ Art. 8.2 Ley 3/1997, de 8 de mayo, de incompatibilidades de los miembros del Gobierno y Altos Cargos de la Administración Pública de la Comunidad Autónoma de Canarias. 


\section{a) Administración del patrimonio personal o familiar}

Resulta razonable, como ha puesto de manifiesto Sarmiento Méndez, que la persona que accede a la condición de alto cargo pueda continuar con la administración de su patrimonio pues no sería lógico que se le impidiese supervisar sus intereses económicos ${ }^{17}$. De este modo, la Ley Andalucía 5/1984 ya disponía, en su artículo 4, que las actividades derivadas de la mera administración el patrimonio personal o familiar no están sujetas al régimen de incompatibilidad. Esta redacción se repite de nuevo en el artículo 5 de la Ley Andalucía 3/2005. La redacción no es muy afortunada, aunque sea la misma que se recoge en la legislación estatal y la mayoría de las disposiciones autonómicas ${ }^{18}$, pues, como bien ha puesto de manifiesto Meseguer Yedra ${ }^{19}$, el término «mera» debe entenderse como una restricción del alcance de lo que es, en efecto, una pura excepción ${ }^{20}$ que es calificada por Sánchez Blanco como una expresión poco afortunada ${ }^{21}$.

${ }^{17}$ X. A. Sarmiento Méndez, (1996), «As incompatibilidades dos membros da Xunta e demáis altos cargos», en Revista Xurídica de la Universidad de Santiago de Compostela, núm. 1, p. 345.

${ }^{18}$ Véanse también, entre otros, los artículos 8.1.d) Ley 13/2005, de 27 de diciembre, del régimen de incompatibilidades de los altos cargos al servicio de la Generalidad -en esta comunidad no se emplea el término mera sino que se recurre al término simple-, 11.a) Ley de Cantabria 1/2008, de 2 de julio, reguladora de los Conflictos de Intereses de los miembros del Gobierno y de los altos cargos de la Administración de Cantabria, 56.a) Ley 8/2003, de 28 de octubre, del Gobierno e Incompatibilidades de sus miembros de la Comunidad Autónoma de la Rioja; art. 10.1 Ley Castilla y León 6/1989, 7.a) Ley 2/1996, de 19 de noviembre, de incompatibilidades de los miembros del Gobierno y de los altos cargos de la Comunidad Autónoma de las Islas Baleares, 8.1 Ley 3/1997, de 8 de mayo, de incompatibilidades de los miembros del Gobierno y Altos Cargos de la Administración Pública de la Comunidad Autónoma de Canarias y 6 Ley Foral 19/1996, de 4 de noviembre, de incompatibilidades de los miembros del Gobierno de Navarra y de los altos cargos de la Administración de la Comunidad Foral de Navarra.

${ }^{19} \mathrm{~J}$. Meseguer Yedra (2007), Régimen de conflictos de intereses e incompatibilidades de los miembros de los miembros del gobierno y altos cargos de la Administración, Bosch, Barcelona, p. 193.

${ }^{20}$ El Grupo Parlamentario Popular solicitó eliminar el término en la enmienda 29 al proyecto de ley estatal.

${ }^{21}$ A. Jiménez Blanco, «Estatuto de los miembros del Gobierno: deberes, derechos e incompatibilidades», en A.A. VV. (Coord. L. Parejo Alfonso), Estudios sobre el Gobierno, Universidad Carlos III y BOE, Madrid, 1996, p. 226. Algunos autores han criticado el empleo del verbo administrar por entender que en el orden jurídico civil se contrapone a disponer y, por tanto, se podría llegar al absurdo de que un ministro no pudiera vender un inmueble de su propiedad. Desde nuestra posición esta interpretación debe ser rechazada pues administrar, en la tercera acepción del Real Diccionario de la Lengua Española, se define como «Ordenar, disponer, organizar, en especial la hacienda o los bienes»y, por tanto, entendemos que la administración también lleva implícito la disposición de los bienes que integran el patrimonio. Véase, Meseguer Yedra (2007: 193-194). 
La Ley Andalucía 3/2005 recoge una excepción al régimen de compatibilidad para la administración del patrimonio personal o familiar, en los supuestos de «participación superior al diez por ciento entre el titular del alto cargo, su cónyuge, pareja de hecho inscrita en el correspondiente Registro, hijos menores y personas titulares en sociedades que tengan conciertos, contratos o concesiones de cualquier naturaleza con el sector público estatal, autonómico o local» ${ }^{22}$. Una previsión similar ya se encontraba en la Ley del 84. Sin embargo, la redacción actual ha mejorado notablemente el anterior en la medida que el primero no contemplaba a las parejas de hecho y personas tuteladas y solo se producían en los supuestos en que la participación fuera superior al diez por ciento en las sociedades que tengan conciertos de obras, servicios o suministros, cualquiera sea su naturaleza, exclusivamente cuando aquéllos fueran con la entidad pública en la que desempeñase su cargo, mientras que con la ley vigente se ha eliminado esta limitación, ampliándose a todo el sector público estatal, autonómico o local.

Esta cautela se ha visto reforzada, en cierta medida, con la obligación que se impone, en el artículo 9 de la Ley Andalucía 3/2005 - que es una reproducción del artículo 8 de la Ley Andalucía 5/1984-, a las empresas, entidades o sociedades que tomen parte en licitaciones públicas, contraten o hayan de encargarse de la gestión de cualquier servicio público, ya sea prestado directamente por la Administración de la Junta de Andalucía o a través de sus entes instrumentales, de acreditar, mediante la oportuna certificación expedida por su órgano de dirección o representación competente, que no forma parte de los órganos de gobierno o administración persona alguna a los que se refiere esta disposición; incumplimiento que supondrá el rechazo de las proposiciones que no acompañen dicha certificación, junto a los documentos requeridos en cada caso.

${ }^{22}$ Véase también, en este mismo sentido, entre otros, los artículos 8.b) Ley Castilla y León 6/1989, 8.a) Ley 13/2005, de 27 de diciembre, del régimen de incompatibilidades de los altos cargos al servicio de la Generalidad; 11.a) Ley de Cantabria 1/2008, de 2 de julio, reguladora de los Conflictos de Intereses de los miembros del Gobierno y de los altos cargos de la Administración de Cantabria; 5.1 Ley Asturias 4/1995, 7.b) Ley 2/1996, de 19 de noviembre, de incompatibilidades de los miembros del Gobierno y de los altos cargos de la Comunidad Autónoma de las Islas Baleares; 4.1 Ley 3/1997, de 8 de mayo, de incompatibilidades de los miembros del Gobierno y Altos Cargos de la Administración Pública de la Comunidad Autónoma de Canarias, 8.1 Ley 3/1997, de 8 de mayo, de incompatibilidades de los miembros del Gobierno y Altos Cargos de la Administración Pública de la Comunidad Autónoma de Canarias y 3.2. Ley Foral 19/1996, de 4 de noviembre, de incompatibilidades de los miembros del Gobierno de Navarra y de los altos cargos de la Administración de la Comunidad Foral de Navarra. 
De esta manera, se articula un nuevo instrumento, al margen de las propias declaraciones exigidas por la Ley a los altos cargos, para la detección de posibles participaciones de altos cargos en sociedades que participen empresas, entidades o sociedades que tomen parte en licitaciones públicas, contraten o hayan de encargarse de la gestión de cualquier servicio público, ya sea prestado directamente por la Administración de la Junta de Andalucía o a través de sus entes instrumentales.

b) Producción y creación literaria, artística, científica y técnica

Resultan compatibles, como manifiesta el artículo 4.2.a) del Decreto Andalucía 176/2005 «las actividades de producción y creación literaria, artística, científica y técnica, así como las publicaciones derivadas de aquellas, podrán efectuarse de forma no habitual y siempre que no sean consecuencia de una relación de empleo o prestación de servicios» ${ }^{23}$.

La creatividad es una manifestación del principio de libertad de expresión, un medio de desarrollo de la personalidad y un derecho reconocido en el artículo 20.1.b) de la Constitución que reconoce el derecho a la «producción y creación literaria, artística, científica y técnica». En consecuencia, no puede ser cercenado por ninguna norma de incompatibilidad, sin embargo, ello no es obstáculo para que se establezca la limitación o la salvedad que introduce el precepto que prohíbe las publicaciones derivadas de aquéllas de forma habitual y que sean consecuencia de una relación de empleo o de una prestación de empleo, pues, en estos supuestos, al existir una relación permanente y habitual se produciría la existencia de «vínculo laboral» que no sería aceptable. Por tanto, no queda limitada, como es lógico, la creación literaria, artística, etc. que pertenecen a la esfera del individuo sino que exclusivamente se limita la publicación de las mismas cuando se derive de una relación de empleo o prestación

${ }^{23}$ Véanse también, entre otros, los artículos 8.1.d), Ley 13/2005, de 27 de diciembre, del régimen de incompatibilidades de los altos cargos al servicio de la Generalidad; 11.b) Ley de Cantabria $1 / 2008$, de 2 de julio, reguladora de los Conflictos de Intereses de los miembros del Gobierno y de los altos cargos de la Administración de Cantabria; 56.b) Ley 8/2003, de 28 de octubre, del Gobierno e Incompatibilidades de sus miembros de la Comunidad Autónoma de la Rioja y 6 Ley Foral 19/1996, de 4 de noviembre, de incompatibilidades de los miembros del Gobierno de Navarra y de los altos cargos de la Administración de la Comunidad Foral de Navarra. El artículo 8.b) Ley Castilla y León 6/1989 completa esta excepción incluyendo que no pueden ser retribuidas las actividades con cargo a fondos de las Administraciones Públicas o entidades dependientes de ellas. 
de servicios ${ }^{24}$. El concepto publicación debe entenderse en un sentido amplio pues existen creaciones que no se publican como por ejemplo, esculturas, pinturas y, por tanto, el término debe entenderse en un sentido finalista.

c) Colaboración y participación en congresos, seminarios, conferencias, jornadas

El artículo 4.2.b) del Decreto Andalucía 176/2005 excluye del régimen de incompatibilidades la colaboración y participación de altos cargos en congresos, seminarios, conferencias, jornadas, coloquios o $\operatorname{cursos}^{25}$. Pero para que se

${ }^{24}$ En este sentido el Tribunal Constitucional, en su Sentencia de 2 de noviembre de 1989 (RTC 1989 178), analiza la posible inconstitucionalidad de la limitación - va referida a la Ley estatal de 1984 pero el contenido es el mismo que el de la Ley Andalucía 3/2005- al considerar los recurrentes que la salvedad establecida condicionaba el ejercicio de la libertad de expresión.

El Alto Tribunal manifestó que «no hay tal condicionamiento, sin embargo, si se tiene en cuenta la finalidad que persigue el precepto, que es, precisamente, excluir del régimen de incompatibilidades - con todas sus consecuencias, incluidas, claro está, las de naturaleza económica- la producción y creación literaria, artística, científica y técnica. Que se haga la salvedad de la producción realizada como consecuencia de una relación de empleo o de prestación de servicios para nada afecta a dicha libertad, sino exclusivamente a la titularidad de la referida producción que, por recaer en el ente público de que se trate, ningún sentido tiene que se exceptúe ese supuesto del régimen de incompatibilidades.

Los demandantes reprochan también la limitación a la ocasionalidad, contenida en los apartados $g$ ) y $h$ ) del repetido precepto, que consideran que infringe, simultáneamente, los arts. $20 \mathrm{y}$ 27 de la Constitución.

La limitación en cuestión es, sin embargo, perfectamente razonable y coherente con el sistema de incompatibilidades establecido en la Ley 53/1984, ya que de no existir esa limitación el ejercicio habitual, reiterado y constante de las actividades a que se refieren los apartados $g$ ) y $h$ ) del art. 19 de la Ley impugnada podría entrar en contradicción con la dedicación al puesto de trabajo en la Administración, con menoscabo de la eficacia de la actividad del correspondiente ente público» (F.J. undécimo).

${ }^{25}$ Véanse también, entre otros, los artículos 8.1.b) Ley 13/2005, de 27 de diciembre, del régimen de incompatibilidades de los altos cargos al servicio de la Generalidad, 7 Ley 2/1996, de 19 de noviembre, de incompatibilidades de los miembros del Gobierno y de los altos cargos de la Comunidad Autónoma de las Islas Baleares y 8.1 Ley 3/1997, de 8 de mayo, de incompatibilidades de los miembros del Gobierno y Altos Cargos de la Administración Pública de la Comunidad Autónoma de Canarias. En esta última Comunidad se prevé que el desempeño de un alto cargo será compatible con la impartición y dirección de seminarios, cursos y conferencias en centros oficiales destinados a la selección, formación y perfeccionamiento de funcionarios, siempre que no tengan carácter permanente o habitual ni supongan más de setenta y cinco horas al año»-art. 7.2 Ley 3/1997, de 8 de mayo, de incompatibilidades de los miembros del Gobierno y Altos Cargos de la Administración Pública de la Comunidad Autónoma de Canarias.--. 
produzca esta compatibilidad se requieren dos requisitos: a) el carácter esporádico y ocasional de la actividad y $b$ ) que no estén financiados específicamente por la Administración de la Juna de Andalucía.

Una aplicación estricta del precepto llevaría pensar que los altos cargos no podrían participar ni colaborar, en modo alguno, cuando la actividad se encuentre financiada por la Junta de Andalucía. Sin embargo, esta interpretación literal debe ser desechada pues debemos entender que el precepto se refiere exclusivamente a las actividades de esta naturaleza ajenas al cargo. No tendría sentido que un Consejero no pudiese pronunciar una conferencia financiada por su propia Consejería cuando su intervención se deba precisamente al cargo que ocupa, lo que no podría es percibir ingreso alguno en virtud de su intervención.

La participación de los altos cargos en el resto de actividades, según algunos autores, puede resultar peligrosa en orden a preservar la imparcialidad de los mismos pues es frecuente que las retribuciones sean cuantiosas y, en numerosas ocasiones, están organizados y/o promovidos por colectivos interesados. Sin embargo, y pese a ello, ninguna de las leyes autonómicas ha prohibido la percepción de cantidades económicas ${ }^{26}$.

En cuanto al requisito de la ocasionalidad, como ha dejado de manifiesto Meseguer Yedra, «es perfectamente razonable y coherente con el sistema de incompatibilidades ya que de no existir esa limitación el ejercicio habitual, reiterado y constante de la actividad (...) podría entrar en contradicción con la dedicación al puesto de trabajo en la Administración, con menoscabo de la eficacia de la actividad del correspondiente Organismo o Ente público» ${ }^{27}$; es decir, podría colisionar con el principio de dedicación exclusiva ${ }^{28}$.

${ }^{26}$ Véase P. García Mexía, Los conflictos de intereses y la corrupción contemporánea, Aranzadi, CizurMenor, 2001, p. 198.

${ }^{27}$ Meseguer Yedra (2007: 197).

${ }^{28}$ En algunas Comunidades Autónomas, como es la del País Vasco, se excepciona de incompatibilidad retributiva y funcional el desempeño de actividades, ocasionales o permanentes, docentes o de investigación en las universidades del País Vasco, en los centros de selección y perfección de funcionarios o en cualquier otro centro de investigación del País Vasco. Esta excepción no requerirá autorización alguna si se realiza fuera del horario de trabajo o se presta en régimen de jornada reducida no superior a cien horas anuales, siendo necesaria autorización si se supera ese límite - art. 5 Ley 32/1983-. En un sentido similar también se encuentra Cataluña que permite que «los altos cargos al servicio de la Generalidad pueden compatibilizar su cargo con el ejercicio de funciones docentes universitarias retribuidas, de carácter reglado, siempre y 


\section{d) Participación en actividades de instituciones culturales o benéfi- cas}

La Ley Andalucía 3/2005 incluye entre las incompatibilidades «el ejercicio de toda clase de actividades en instituciones culturales o benéficas, salvo autorización del órgano que los nombró o que fueran ajenas al cargo» - art. 6.f)-, y posteriormente el Decreto Andalucía 176/2005 le da una redacción positiva a esta incompatibilidad permitiéndola cuando sean autorizadas o sean ajenas al cargo -art. 4.2.b) ${ }^{29}$.

cuando no sea en detrimento de la dedicación al ejercicio del cargo público, en régimen de dedicación a tiempo parcial y con una duración determinada» y en todo caso se requiere autorización expresa del consejero o consejera competente en materia de función pública -art. 11 Ley 13/2005, de 27 de diciembre, del régimen de incompatibilidades de los altos cargos al servicio de la Generalidad-. En este conjunto de Comunidades Autónomas también se integra Cantabria que permite la compatibilidad del cargo con el desempeño de actividades docentes o de investigación en centro universitarios, en el Centro de Estudios de la Administración Pública Regional de Cantabria u otros centros de selección y perfeccionamiento de empleados públicos, o en cualesquiera otros centros de investigación, siempre que tales actividades no supongan menoscabo de la dedicación al cargo. En los supuestos en que esta dedicación sea regular se requiere la autorización del Consejero de la Presidencia y Justicia y del Gobierno cuando se trate de Consejeros. En esta Comunidad se limita las retribuciones que no podrán superar el treinta por ciento de la que corresponde al alto cargo - art. 10.e) Ley de Cantabria 1/2008, de 2 de julio, reguladora de los Conflictos de Intereses de los miembros del Gobierno y de los altos cargos de la Administración de Cantabria-. En la Comunidad Canaria, se requiere autorización expresa del Gobierno - art. 7.1 Ley 3/1997, de 8 de mayo, de incompatibilidades de los miembros del Gobierno y Altos Cargos de la Administración Pública de la Comunidad Autónoma de Canarias-. En Galicia, por el contrario, no se delimita el tipo de docencia incluyéndose «el ejercicio de funciones docentes, de carácter reglado...»-art. 5 Ley 9/1996, de 18 de octubre, de incompatibilidades de los miembros de la Junta de Galicia y altos cargos de la administración autonómica-

${ }^{29}$ Algunas Comunidades Autónomas, como es el caso de Cataluña, no contemplan esta modalidad de excepción al régimen de incompatibilidad y exclusivamente se refiere a la participación en entidades sin ánimo de lucro - art. 8.1.e) Ley 13/2005, de 27 de diciembre, del régimen de incompatibilidades de los altos cargos al servicio de la Generalidad-.. Otras Comunidades requieren que las entidades benéficas o culturales no tengan ánimo de lucro para poder reconocer la compatibilidad como es el caso de la Comunidad Balear -art. 7.d) Ley 2/1996-, mientras otras exigen la ausencia de ánimo de lucro y la ausencia de retribución alguna -arts. 56.c) Ley 8/2003, de 28 de octubre, del Gobierno e Incompatibilidades de sus miembros de la Comunidad Autónoma de la Rioja, 7 Ley 9/1996, de 18 de octubre, de incompatibilidades de los miembros de la Junta de Galicia y altos cargos de la administración autonómica, 8.1 Ley 3/1997, de 8 de mayo, de incompatibilidades de los miembros del Gobierno y Altos Cargos de la Administración Pública de la Comunidad Autónoma de Canarias y 6 Ley Foral 19/1996, de 4 de noviembre, de incompatibilidades de los miembros del Gobierno de Navarra y de los altos cargos de la Administración de la Comunidad Foral de Navarra- 
Antes de entrar en diversas consideraciones sobre la excepción expuesta, es necesario realizar una observación que va referida a una cuestión de economía normativa pues con la redacción del artículo 6.f) de la Ley no era necesaria la precisión del Decreto en la medida que la excepción ya se encontraba recogida junto a la causa de incompatibilidad; circunstancia que no se producía en los supuestos anteriores.

$\mathrm{Al}$ margen de esta cuestión, y entrando en el contenido material del precepto, podemos afirmar que, con el régimen articulado, los altos cargos podrán desempeñar toda clase de actividades en instituciones culturales o benéficas cuando fueran anejas al cargo y en los demás supuestos requerirá autorización.

Con todo, lo cierto es que la redacción de la excepción es parca por dos motivos:

a) No se precisa a qué tipo de actividades se refiere, pues con la redacción actual parece que no hay excepción, cualquier tipo o modalidad de participación requerirá la autorización, salvo que sea ajena al cargo. En este sentido, de lege ferenda, se podría condicionar en todo caso la participación a que no comprometa la imparcialidad o la independencia del cargo.

b) No se concreta qué características deben tener las instituciones culturales o benéficas, ¿pueden tener ánimo de lucro? ¿Cuál es la delimitación de su ámbito territorial?...

Ante esta situación, proponemos una modificación sustancial del precepto con objeto de dotarlo de la entidad suficiente para aclarar esos extremos y aportar seguridad jurídica y transparencia a la cuestión.

\section{Actividades públicas compatibles}

En la Ley se distinguen dos ámbitos públicos de compatibilidad: uno representativo, de carácter personal y de una legitimación directa como es el de parlamentario, y otro de carácter representativo, institucional y de legitimación indirecta, vinculados o no a la condición de alto cargo, que les permite formar parte de los órganos colegiados o de otra naturaleza de las Administraciones Públicas cuando les corresponda con carácter institucional o para los que fuesen designados en función del cargo y de representar a la Administración de la Junta de Andalucía en los órganos de gobierno o consejos de administración de empresas con capital público -art. 3.2 y 4 Ley Andalucía 3/2005-. 


\section{RÉGIMEN DEL DEBER DE PRESENTACIÓN DE ACTIVIDADES, BIENES E INTERESES}

La Ley Andalucía 5/1984, en su artículo décimo, establecía la obligación de los altos cargos de formular declaración sobre las causas de incompatibilidad en la que debería constar, por tanto un declaración de mínimos, la referencia a las actividades lucrativas profesionales, laborales, mercantiles o industriales $^{30}$. Sin embargo, la Ley no exigía la declaración de los bienes patrimoniales que quedaban fuera de control y esta situación persistiría hasta la aprobación de la Ley 4/1990, de 23 de abril, por la que modifican determinados artículos de la Ley 5/1984, y por la que se añade un punto tercero al artículo 10 en el que se dispone que «los Altos Cargos a que hace referencia esta Ley formularán además declaración de bienes patrimoniales». Posteriormente, este precepto sufriría una nueva modificación por la Ley 3/1994, de 5 de abril, por la que se determina la incorporación de las declaraciones tributarias al Registro de intereses y bienes de los altos cargos de la Junta de Andalucía, quedando como texto definitivo hasta la derogación de la Ley Andalucía 5/1984 por la Ley Andalucía 3/2005, manifestando que «Los titulares de cargos a que hace referencia esta Ley formularán declaración sobre las causas de posible incompatibilidad con arreglo al modelo que aprobará la Consejería de Gobernación. En dicho modelo deberá constar la referencia a las actividades lucrativas, profesionales, laborales, mercantiles o industriales de quienes accedan a los Altos Cargos, así como declaración de bienes patrimoniales, con expresión de su situación y valor a la fecha de la declaración, incorporando copia de la declaración-liquidación del Impuesto sobre la Renta de las Personas Físicas y la del Impuesto sobre el Patrimonio, en caso de estar obligado a ello» (art. 10.1).

Para el cumplimiento de esta obligación el artículo 10 de la Ley Andalucía 5/1984 manifestaba que la declaración por parte de los altos cargos se re-

30 Como manifiesta Meseguer Yebra (2007: 213), «muchos países, entre ellos la mayoría de los incluidos en los estudios del Comité de Administración Pública (PUMA), constituido en el seno de la OCDE, como es el caso de Finlandia, Países Bajos, Reino Unido, Estados Unidos y Australia, poseen instrumentos semejantes al regulado en este precepto, esto es, una declaración de bienes y patrimonio que en algunos sistemas, incluso, se aplica no sólo a altos cargos y miembros del Gobierno, sino también a determinados funcionarios públicos de alto nivel». Con la Ley estatal 5/2006 «se logra extender la obligación de efectuar declaración patrimonial para todo el ámbito subjetivo de aplicación del régimen de incompatibilidades de altos cargos, dado que con la Ley 25/1983, de 26 de diciembre, sólo debían formularla los miembros del Gobierno, secretarios de Estado, subsecretarios y asimilados». 
alizaría con arreglo a un modelo que aprobaría la Consejería de la Presidencia, sin que se estableciese plazo para ello. Posteriormente se atribuiría esta obligación a la Consejería de Gobernación, mediante la Ley 3/1994, de 5 de abril, por la que se determina la incorporación de las declaraciones tributarias al Registro de intereses y bienes de los altos cargos de la Junta de Andalucía, y en el Decreto 140/1992, de 28 de julio, se asignó a la Inspección General de Servicios. Esta competencia pasaría, por Decreto del Presidente 6/2000, de 28 de abril, sobre la reestructuración de Consejerías, a la Consejería de Justicia y Administración Pública al atribuirle las competencias que tenía la Dirección General de Organización Administrativa e Inspección de Servicios para pasar a la Dirección General de Organización, Inspección y Calidad de los Servicios, que pasó a denominarse Dirección General de Inspección y Evaluación de Servicios por el Decreto 305/2008, por el que se establece la estructura orgánica de la Consejería de Justicia y Administración Pública y que ha sido suprimida en el organigrama de la Consejería de Hacienda y Administración Pública (Decreto 133/2010).

Es significativo que después de todo este periplo no fuese hasta el 2004 cuando, a través de Resolución de 7 de enero de la Dirección General de Organización, Inspección y Calidad de los Servicios, se aprobase el modelo de declaración de actividades y bienes patrimoniales de Altos Cargos de la Administración de la Junta de Andalucía.

La Ley Andalucía 3/2005, a diferencia de su antecesora con todas las modificaciones que sufrió, en esta materia es mucho más parca ya que se limita a recoger la obligación de los altos cargos de formular declaración de sus actividades, bienes e intereses, conforme se establezca reglamentariamente y exigir la presentación de copia de la declaración del Impuesto sobre la Renta de la Personas Físicas y, en su caso, del Impuesto sobre Patrimonio de cada ejercicio económico. Por el contrario, el Reglamento, Decreto Andalucía 176/2005, resulta muy preciso.

\section{Deber de declaración de los altos cargos}

La Ley Andalucía 3/2005, en su artículo 11, recoge la obligación de los altos cargos y otros cargos públicos de formular la declaración de sus actividades, bienes e intereses, conforme a lo que se establezca reglamentariamente, es decir, conforme al capítulo II del Decreto Andalucía 176/2005 que, en cuanto a la obligación, reproduce, en su artículo 8.1, el contenido del precepto de la Ley. En este sentido resulta obligado señalar que la normativa andaluza, al igual que el resto, establece la obligación de declarar, el contenido de dicha de- 
claración, el plazo y otras cuestiones pero no determina el momento de partida de esa declaración y, por tanto, se entiende que debe versar sobre las actividades, bienes e intereses existentes en el momento del nombramiento y del cese. Sin embargo, si el fin teleológico de esta medida es la transparencia del patrimonio de los altos cargos a lo largo del desarrollo de su función con objeto de eliminar toda duda sobre posibles enriquecimientos durante el mismo, de lege ferenda proponemos que la declaración debe abarcar las actividades, bienes e intereses con una anterioridad al nombramiento de un año solo de esta manera puede evitarse que se realicen operaciones de maquillaje justo antes del acceso al cargo ${ }^{31}$.

\section{La obligación de informar a los altos cargos de sus obliga- ciones en materia de incompatiblidad}

La normativa andaluza articula un cauce de información, en el artículo 16 del Decreto Andalucía 176/2005, bajo la rúbrica información en materia de incompatibilidades, para que los nuevos cargos conozcan las obligaciones que se derivan de su nombramiento. De esta manera se impone, de forma genérica, a la Dirección General de Inspección y Evaluación de Servicios ${ }^{32}$, la obligación de

${ }^{31}$ En el caso, entre otras, de la Comunidad de Madrid de exige, aunque se refiera exclusivamente a las actividades, la obligación de efectuar declaración de todas las actividades desempeñadas por sí o mediante sustitución o apoderamiento, durante al menos el último año anterior a la toma de posesión (art. 9 Ley 14/1995, de 21 de abril, de incompatibilidades de Altos Cargos de la Comunidad de Madrid).

${ }^{32}$ En los Decretos 132/2010, de 13 de abril, por el que se establece la estructura orgánica de la Consejería de Gobernación y Justicia, y 133/2010, de 13 de abril, por el que se regula la estructura orgánica de la Consejería de Hacienda y Administración Pública, fruto del Decreto del Presidente 14/2010, de 22 de marzo, sobre reestructuración de Consejerías, no se contempla la Dirección General de Inspección y Evaluación de servicios. Esta situación podría hacer surgir la duda sobre qué Consejería ejercerá las funciones establecidas en el Decreto 176/2005 a esa Dirección General, pero esta duda queda resuelta en el artículo 3.2 del Decreto del Presidente 14/2010, cuando se asignan «a la Consejería de Hacienda y Administración Pública las competencias actualmente atribuidas a la Consejería de Justicia y Administración Pública ejercidas a través de la Secretaría General para la Administración Pública, la Dirección General de Modernización e Innovación de los Servicios Públicos, la Dirección General de la Función Pública y la Dirección General de Inspección y Evaluación de Servicios» (art. 3.2). Sin embargo, el problema es relativamente más complejo si intentamos determinar a qué centro directivo de la Consejería de Hacienda y Administración Pública debemos entender ahora, referidos a las obligaciones y cometidos atribuidos por el Decreto 176/2005 a la Dirección General de Inspección y Evaluación de Servicios. El Decreto 133/2010, de 13 de abril, por el que se regula la estructura orgánica de la Consejería de Hacienda y Administración Pública, no nos proporciona una directa solución pero podríamos entender que deberían ir referidos a la Secretaría General para la 
divulgar las obligaciones en materia de incompatibilidades, pero esta obligación se complementa, a su vez, con la obligación de información a los altos cargos de las obligaciones en materia de incompatibilidades en dos supuestos. El primero de ellos requiere un comportamiento activo y previo por parte de la Dirección General, pues esta obligación surgirá cuando esta tenga conocimiento del nombramiento o cese de un alto cargo como consecuencia de su publicación en el Boletín Oficial de la funta de Andalucía. En el segundo supuesto, el conocimiento de la Dirección General del nombramiento del alto cargo es consecuencia de la obligación impuesta a las Consejerías, Organismos Autónomos, entidades de Derecho público, empresas públicas, fundaciones y consorcios con participación directa de la Junta de Andalucía superior al 50 por 100, de comunicar a la Dirección General de Inspección y Evaluación en el plazo de un mes, los nombramientos y ceses que efectúen siempre que correspondan a cargos comprendidos en el $\infty$ ámbito de aplicación del artículo 2 de la Ley $3 / 2005^{33}$. Todo ello sin perjuicio de la obligación que se impone a las Secretarías Generales Técnicas de las Consejerías de divulgar las obligaciones que se derivan de la Ley Andalucía 3/2005 entre todos los altos cargos y otros cargos públicos de las mismas, organismos autónomos, entes, empresas públicas, fundaciones y consorcios dependientes de ellas.

\section{Contenido de las declaraciones de actividades, bienes e in- tereses}

La Ley no concreta, como tampoco hacía su antecesora, las actividades, bienes e intereses que deben ser declarados por los altos cargos, remitiendo a un ulterior desarrollo reglamentario ${ }^{34}$. En este caso, en el Decreto Andalucía

Administración Pública en la medida que se hace depender, orgánica y funcionalmente, de ella la Inspección General de Servicios, que desempeñará las funciones atribuidas por el Decreto 314/202, de 30 de diciembre, por el que se aprueba el Reglamento de la Inspección General de Servicios de la Junta de Andalucía, entre otras, en materia de incompatibilidades. Sin embargo, este Decreto exclusivamente contempla, como función en materia de incompatibilidades de altos cargos, «la custodia y gestión del Registro de Intereses y Bienes, de acuerdo con la normativa vigente sobre la materia» $y$, por tanto, el resto de funciones que se atribuían a la supresa Dirección General quedan en una situación de extraña indeterminación competencial.

${ }^{33}$ Véase el artículo 14 Decreto Andalucía 176/2005.

${ }^{34}$ La proposición de ley (8-11/PPL-000008), presentada por Grupo Parlamentario Socialista, actualmente en curso, incide sobre esta cuestión y establece que:«Los altos cargos y otros cargos públicos estarán obligados, conforme se establezca reglamentariamente, a formular declaración de sus actividades, bienes, intereses y retribuciones.

Dicha declaración se extenderá, conforme se establezca reglamentariamente, a las relaciones en materia de contratación con todas las Administraciones públicas y entes participados de los 
176/2005 se ha realizado un ejercicio plausible consistente en precisar explícitamente el contenido aportando seguridad jurídica a la materia pues durante la vigencia de la Ley anterior era una Resolución, concretamente por la que se aprobaba el modelo de declaración de actividades y bienes patrimoniales de los Altos Cargos, de 7 de enero de 2004, la que precisaba estos aspectos.

El artículo 9 del Decreto Andalucía 176/2005 dispone que la declaración reflejará, al menos, los siguientes aspectos:

- Cargos y actividades públicas para los que ha sido designado y aquéllos que le corresponden con carácter institucional.

- Pensiones de derechos pasivos o de la Seguridad Social.

- Actividades públicas y privadas que desempeñen por cuenta propia o ajena.

- Bienes inmuebles urbanos y rústicos.

- Saldo en cuentas bancarias a la fecha de nombramiento y cese.

- Acciones y participaciones en capital de sociedades, títulos de deuda pública, fondos de inversión, certificados de depósitos y otros valores mobiliarios, a la fecha de nombramiento y cese y con el deber de actualizarlos a 31 de diciembre de cada año.

- Objeto social de las sociedades de cualquier clase en las que tengan intereses.

- Bienes muebles y otros bienes y derechos de cualquier clase o naturaleza que posean, cuyo valor supere los 6.000 euros.

- Seguros de vida cuya indemnización supere la cifra de 30.000 euros.

- Créditos, préstamos o deudas que integren el pasivo.

miembros de la unidad familiar de los altos cargos y de otros cargos públicos, de acuerdo con los establecido en la Ley 35/2006, de 28 de noviembre, del Impuesto sobre la Renta de las Personas Físicas y de modificación parcial de las leyes de los Impuestos sobre Sociedades, sobre la Renta de no Residentes y sobre el Patrimonio» (BOPA núm. 736/2011, de 2 de septiembre). 
Sin embargo, para salvaguardar la privacidad y la seguridad de los altos cargos, se establecen una serie de cautelas en cuanto a determinados bienes e intereses; concretamente bienes inmuebles, cuentas bancarias y valores mobiliarios, y vehículos y embarcaciones. Y así, de los bienes inmuebles se omitirán los datos referentes a su localización, incluyéndose exclusivamente sus características, provincia en que se hallen y el valor catastral; de las cuentas bancarias y valores mobiliarios solo se detallará el saldo existente a la fecha de nombramiento y cese, sin olvidar que se deben actualizar a 31 de diciembre de cada año, y, por último en lo que respecta a vehículos y embarcaciones sólo se especificará marca, modelo y valor, determinándose su valor en base a los precios medios de venta que anualmente aprueba el Ministerio de Economía y Hacienda para la gestión del Impuesto sobre Transmisiones Patrimoniales y Actos Jurídicos Documentados, Impuesto sobre Sucesiones y Donaciones e Impuesto sobre Determinados Medios de Transporte. En cuanto a los restantes bienes, se empleará el criterio de valoración del Impuesto sobre el Patrimonio $^{35}$.

En el supuesto de bienes y derechos indivisos se indicará el valor que corresponda según el porcentaje de participación del declarante en el bien o derecho correspondiente.

\section{Formas y plazo de presentación de las declaraciones}

Las declaraciones, como establece el artículo 10 del Decreto Andalucía 176/2005, irán dirigidas a la Dirección General de Inspección y Evaluación, ahora Dirección General de Inspección y Evaluación de Servicios ${ }^{36}$, y deberán cumplimentarse siguiendo el modelo que se encuentra en el anexo del Decreto ${ }^{37}$.

Podrá optarse por dos formas de presentación: una «tradicional», consistente en la presentación por escrito en el Registro General de la Conseje-

35 La Ley 19/1991, de 6 de junio, sobre el Impuesto de Patrimonio se ha visto afectada por la Ley 4/2008, de 23 de diciembre, en la medida que el impuesto ya no se devenga pero la Ley continúa vigente y, por tanto, los criterios a los que alude el precepto también.

${ }^{36}$ Véase nota 32.

${ }^{37}$ Este anexo del Decreto Andalucía 176/2005 supone la derogación implícita de la Resolución de 7 de enero de 2004, de la Dirección General de Organización, Inspección y Calidad de los Servicios, por la que se aprueba el modelo de declaración de actividades y bienes patrimoniales de Altos Cargos de la Administración de la Junta de Andalucía. 
ría de Hacienda y Administración Pública o en cualquiera de los lugares previstos en el artículo 38.4 de la Ley 30/1992, o telemática, a través del Registro Telemático único de la Administración de la Junta de Andalucía mediante el portal www.andaluciajunta.es, debiendo, el alto cargo, disponer de un certificado reconocido de usuario que le habilite a utilizar la firma electrónica avanzada.

Una vez recibidas las declaraciones en el Registro, corresponde a la Dirección General de Inspección y Evaluación de Servicios ${ }^{38}$ examinar la documentación presentada. En los supuestos, como dispone el artículo 17 del Decreto Andalucía 176/2005, en que se apreciasen carencias documentales o deficiencias formales en la declaración ${ }^{39}$, se requerirá a la persona interesada para que, en el plazo de diez días, subsane la falta o acompañe los documentos preceptivos; teniendo presente que si por la documentación presentada, denuncia u otros medios, se tuviese conocimiento que la persona interesada pudiese estar incurriendo en alguna de las causas de incompatibilidad, el titular de la Dirección General de Inspección y Evaluación ${ }^{40}$ lo pondrá en conocimiento de quien ostente la titularidad de la Consejería de Hacienda y Administración Pública para el ejercicio de la acciones pertinentes que procedan según el caso.

En cuanto al plazo para la presentación de las declaraciones, la Ley Andalucía 3/2005 dispone que «la declaración se efectuará en el momento de la toma de posesión, cese o modificación de las circunstancias de hecho...», pero el precepto continúa manifestando que debe hacerse en el plazo que se determine reglamentariamente. Esta redacción no resulta afortunada en la medida que parece que los altos cargos están obligados a presentar la declaración en el momento de la toma de posesión, cese..., pero sin embargo después se remite a un plazo a determinar por reglamento. La única solución interpretativa po-

38 Véase la nota 32. Recordemos que el artículo 13 del Decreto Andalucía 176/2005 manifiesta que «el Registro de actividades, bienes e intereses dependerá de la Consejería de Justicia y Administración Pública, y estará a cargo de la Dirección General de Inspección y Evaluación, a quien corresponde la gestión y control del mismo».

${ }^{39} \mathrm{El}$ artículo 17.3 del Decreto considera deficiencias formales: a) Omisión de cualquiera de los datos identificativos de la persona declarante; $b$ ) Confusión, error o imprecisión en las declaraciones de actividades, bienes e intereses; c) La existencia, en las declaraciones, de palabras tachadas, enmendadas o entre renglones, que no estuvieran salvadas por la persona declarante con su firma y $d$ ) Falta de firma de la persona interesada.

${ }^{40}$ Véase la nota 32. 
sible consiste en entender que la toma de posesión, cese... sirven para determinar el dies a quo y corresponde al reglamento fijar el dies ad quem y únicamente de esta manera se logra dar coherencia a la previsión contenida en el precepto y esta es precisamente la interpretación que ha seguido el artículo 8.2 del Decreto Andalucía 176/2005.

Este último precepto fija el plazo en dos meses desde la toma de posesión $^{41}$, cese o modificación de las circunstancias para presentar las declaraciones ${ }^{42}$; salvo en el caso de las cuentas bancarias de las que solo deberá declararse el saldo a la fecha de toma de posesión y al momento del cese y, como hemos indicado anteriormente para los valores mobiliarios (es decir, acciones, participaciones en capital de sociedades, títulos de deuda pública, fondos de inversión, certificados de depósitos y otros valores mobiliarios) que deberán declararse a fecha del nombramiento y del cese, debiéndose actualizar a 31 de diciembre de cada año ${ }^{43}$.

En el supuesto de que el alto cargo no haya cumplido con su obligación de presentar las declaraciones en el Registro de actividades, bienes e intereses en el plazo de dos meses, previsto en el artículo 8.2 del Decreto Andalucía 176/2005, la Dirección General de Inspección y Evaluación de Servicios le requiera para que las presente en el plazo de diez días ${ }^{44}$. Transcurrido el plazo para realizar las declaraciones y efectuado el requerimiento, la Dirección Ge-

${ }^{41}$ El plazo establecido de dos meses en Andalucía es el más común -La Rioja: art. 58.3 Ley 8/2003 y 15 Decreto 30/2004; Asturias: art. 8.2 Ley 4/1995; Navarra: art. 12.2 Ley 19/1996; Murcia: art. 14.1 Ley 5/1994; Madrid: art. 10 Ley 14/1995 o Extremadura: art. 6 Ley 5/1996aunque también hay excepciones como, por ejemplo, en Cataluña - art. 13 y 6 Decreto 261/1992, Cantabria -art. 15 Ley 1/2008-, El País Vasco, -art. 11 Decreto 129/1999- y Canarias - art. 9.3 Ley 3/1997- que prevén un plazo de tres meses desde el nombramiento.

42 En la Ley Andalucía 5/1984 el plazo establecido era de tres meses siguientes a la toma de posesión o la modificación de las circunstancias de hecho (art. 10.2). Este plazo fue reducido a dos meses por la Ley 3/1994, de 5 de abril, por la que se determina la incorporación de las Declaraciones Tributarias al Registro de Intereses y Bienes de Altos Cargos de la Junta de Andalucía.

${ }^{43}$ En un sentido similar, también encontramos situaciones particulares, como Murcia que prevé el plazo de dos meses pero reduce el tiempo en el caso del cese a un mes (art. 14.1 Ley 5/1994, de 1 de agosto, del Estatuto Regional de la Actividad Política de la Comunidad de Murcia) o Cataluña que para los casos de modificación delimita el tiempo de presentación de la declaración a un mes.

${ }^{44}$ Véase la nota 32. 
neral pondrá los hechos en conocimientos, de quien ostente la titularidad de la Consejería de Hacienda y Administración Pública para que, entendemos, se proceda a la apertura del correspondiente expediente sancionador (art. 16.5 Decreto Andalucía 176/2005) ${ }^{45}$.

\section{Consecuencias jurídicas de la falta de presentación de las declaraciones}

El Decreto Andalucía 176/2005 prevé, en el caso de que el alto cargo no haya cumplido con su obligación de presentar sus declaraciones en el Registro de actividades, bienes e intereses en el plazo de dos meses, previsto en el artículo 8.2 de esta misma norma, que la Dirección General de Inspección y Evaluación de Servicios le requiera para prestarlas en el plazo de diez días ${ }^{46}$. Transcurrido el plazo para realizar las declaraciones y efectuado el requerimiento, la Dirección General pondrá los hechos en conocimiento de quien ostente la titularidad de la Consejería de Hacienda y Administración Pública para, entendemos, se proceda a la apertura del correspondiente expediente sancionador (art. 16.5 Decreto Andalucía 176/2005).

Esta fórmula no resulta aceptable ya que parece que hace depender de un requerimiento previo de una obligación en mora, el inicio de un posible expediente sancionador. Estas posiciones se ven confirmadas con la lectura de los tipos contemplados en el artículo 15 de la Ley Andalucía 3/2005. Así, en primer lugar, el artículo 15.2.d) de la Ley Andalucía 3/2005 califica como infracción grave «la no declaración de actividades, bienes e intereses, en el correspondiente Registro, tras el requerimiento para ello» y, en segundo lugar, el artículo 15.3 del mismo texto tipifica como infracción leve «la no declaración de actividades, bienes e intereses en el correspondiente Registro, dentro de los plazos establecidos, cuando se subsane tras el requerimiento que se formule al efecto».

\footnotetext{
45 Véase el epígrafe Consecuencias jurídicas de la falta de presentación de las declaraciones.

${ }^{46}$ Véase la nota a pie 32 . No debemos confundir este requerimiento con la subsanación prevista en el artículo 17 del Decreto Andalucía 176/2005, abordada en el epígrafe correspondiente a la presentación de las solicitudes, pues en este caso se ha cumplido la obligación de presentación de la declaración en plazo con independencia de los defectos formales o carencias documentales que pudiera tener mientras que en el requerimiento se parte de la premisa de la falta de cumplimiento de la obligación prevista.
} 
De esta manera, y en ambos casos, el requerimiento se convierte en un elemento del tipo sin el cual no será posible apreciar la existencia de la infracción que deriva en una situación de «favor» que carece de justificación alguna pues existe la obligación de la Dirección General ${ }^{47}$ y de las Secretarias Generales Técnicas de informar a los altos cargos de sus obligaciones en materia de incompatibilidad. Pero aún en el hipotético caso de que no se hubiera procedido a informar a los mismos no es un argumento para el incumplimiento de los deberes impuestos y aún menos para que sea perseguible la omisión, pues en el primer caso parece que lo que se sanciona en la Ley no es el incumplimiento de la obligación impuesta sino la falta de atención al requerimiento y en el segundo, el retraso en el cumplimiento una vez detectado. Es por ello que no nos parece de recibo condicionar la apertura de un posible expediente sancionador a un previo requerimiento proponiendo, por tanto, de lege ferenda la supresión de este requisito del tipo del artículo 15.2.d) de la Ley Andalucía y la eliminación del mismo del artículo 16.3, 4 y 5 del Decreto Andalucía 176/2005.

\section{Transparencia de las declaraciones: publicidad}

La Ley Andalucía 3/2005 dispone, en su artículo 14, que el Registro de Actividades, Bienes e Intereses será público y a su vez manifiesta que el contenido de las declaraciones inscritas se publicarán en el Boletín Oficial de la Junta de Andalucía y estarán disponibles en Internet, concretamente en la página web de la Consejería de Hacienda y Administración Pública -art. 14.2-48, con la excepción de las declaraciones del impuesto de la renta - art. 12.2 Ley Andalucía 3/2005 y 14.3 Decreto Andalucía 176/2005-49.

Este régimen no es predicable al resto de Comunidades Autónomas que son más recelosas a mostrar la información concerniente a los altos cargos; especialmente la relativa a los bienes y derechos patrimoniales que se inserta en un Registro o en una sección registral, según el caso, que tiene un carácter re-

\footnotetext{
47 Véase la nota 32.

48 Concretamente la página es la siguiente: https://ws037.juntadeandalucia.es/riibp/publica/buscaracp.do

${ }^{49}$ En este sentido, la exposición de motivos de la proposición de ley presentada por el Grupo Parlamentario Popular, (8-11/PPL-000010) cuando manifiesta que «unos responsables públicos y una Administración tranparentes y ejemplares constituyen un requisito sine qua non para construir y desarrollar una Administración Pública de calidad, generar confianza y prestar un mejor servicio a la sociedad» (BOPA núm. 736/2011, de 2 de septiembre).
} 
servado $^{50}$ y exclusivamente se permite el acceso con carácter general al Parlamento, a los órganos judiciales, al Ministerio Fiscal y al Defensor del Pueblo ${ }^{51}$ y, en algunas Comunidades, al Consejo de Gobierno, como es el caso, por ejemplo, de Madrid, País Vasco o La Rioja ${ }^{52}$.

La transparencia, por tanto, se erige como un valor fundamental de la legislación andaluza de altos cargos que conduce a Andalucía a situarse en primera línea ${ }^{53}$. Esta cuestión no es baladí, pues como diría el Senado americano con la publicidad de las declaraciones se produce: a) aumento de la confianza de los ciudadanos en las instituciones; $b$ ) la constatación de altos niveles de integridad en la gran mayoría de los cargos o funcionarios; c) la evitación del surgimiento de conflictos de intereses; d) la disuasión frente a la ocupación de funciones y cargos públicos por parte de personas de suficiente integridad y e) una capacitación mas satisfactoria de los ciudadanos para juzgar el rendimiento de sus cargos y funcionarios ${ }^{54} \mathrm{y}$, en último caso, la publicidad permite dejar al descubierto los propios principios éticos que se recogen el punto primero del anexo de la Orden 516/2005, de 3 de marzo, que dispone la publicación del Acuerdo del Consejo de Ministros de 18 de febrero de 2005, por el que se aprueba el Código de Buen Gobierno de los miembros del Gobierno y de los altos cargos de la Administración General del Es-

${ }^{50}$ Véanse, entre otros, los artículos 16 Ley de Cantabria 1/2008, de 2 de julio, reguladora de los Conflictos de Intereses de los miembros del Gobierno y de los altos cargos de la Administración de Cantabria; 14.5 Ley 13/2005, de 27 de diciembre, del régimen de incompatibilidades de los altos cargos al servicio de la Generalidad; 13 Decreto La Rioja 30/2004; 9.3 Ley Asturias 4/1995; 14.4 Ley 14/1995, de 21 de abril, de incompatibilidades de Altos Cargos de la Comunidad de Madrid; 4.2 Decreto Galicia 165/1995; 10.2 Ley 2/1996, de 19 de noviembre, de incompatibilidades de los miembros del Gobierno y de los altos cargos de la Comunidad Autónoma de las Islas Baleares; 8 Decreto Canarias 195/1997; 15.4 Decreto Murcia 5/1994 y 15 Decreto País Vasco 129/1999.

${ }^{51}$ En País Vasco también se permite el acceso al Consejero del que dependa -art. 15 Decreto País Vasco 129/1999-.

52 Véanse los artículos 15 Decreto País Vasco 129/1999, 13.b) Decreto La Rioja 30/2004 y 14.5 Ley 14/1995, de 21 de abril, de incompatibilidades de Altos Cargos de la Comunidad de Madrid.

53 De esta manera si accedemos a las declaraciones de cualquier alto cargo andaluz podremos apreciar, en primer lugar la declaración de actividades, la declaración de bienes patrimoniales - bienes inmuebles, saldo total de las cuentas bancarias, planes de pensiones, automóviles...- y las deudas o créditos existentes.

54 Véase García Mexía, (2001: 195). 
tado, que son: credibilidad, dedicación al servicio público, transparencia, ejemplaridad, austeridad y honradez. Sin embargo, la publicidad del patrimonio del alto cargo puede plantear algunas dudas pues es muy distinto la obligación de declararlo, cuya oportunidad y necesidad resultan evidentes e incuestionables, que la publicidad del mismo en la medida que se podría poner en riesgo al alto cargo al hacer público su patrimonio y, no solo el suyo, sino el de su cónyuge que implícitamente queda reflejado por ejemplo con los bienes inmuebles. Lo más llamativo es que, al publicarse también en el $B 0^{-}$ letín Oficial de la Funta de Andalucía, muchos años después de su cese cualquiera podría conocer el patrimonio del ex alto cargo en aquel momento, produciéndose un atentado contra el principio de proporcionalidad. Es cierto que en la normativa se prevé en la normativa que, transcurrido dos años desde el cese, la persona que ostente la titularidad de la Dirección General de Inspección y Evaluación de Servicios ${ }^{55}$ procederá a la cancelación de los datos obrantes en el Registro pero, como hemos visto, no evitará o cancelará los datos publicados en el Boletín Oficial ${ }^{56}$. Por este motivo, proponemos de lege ferenda no tanto establecer el carácter reservado de los bienes patrimoniales como restringir el acceso exclusivamente a aquéllos que manifiesten un interés legítimo.

55 Véase la nota 32.

56 Véase, sobre los límites al acceso a documentos administrativos por interés privado y el derecho a la intimidad, S. Fernández Ramos, El derecho de acceso a los documentos administrativos, Marcial Pons, Madrid, 1997, p. 487 y ss. 


\section{Cuadro resumen del régimen de las declaraciones}

\begin{tabular}{|c|c|c|}
\hline Contenido & \multicolumn{2}{|c|}{$\begin{array}{l}\text { Cargos y actividades públicas para los que ha sido designado y aquellos que } \\
\text { le corresponden con carácter institucional. } \\
\text { Pensiones de derechos pasivos o de la Seguridad Social. } \\
\text { Actividades públicas y privadas que desempenen por cuenta propia o ajena. } \\
\text { Bienes inmuebles urbanos y rústicos. } \\
\text { Saldo en cuentas bancarias a la fecha de nombramiento y cese. } \\
\text { Acciones y participaciones en capital de sociedades, títulos de deuda pública, } \\
\text { fondos de inversión, certificados de depósitos y otros valores mobiliarios, a la } \\
\text { fecha de nombramiento y cese, y con el deber de actualizarlos a } 31 \text { de di- } \\
\text { ciembre de cada año. } \\
\text { Objeto social de las sociedades de cualquier clase en las que tengan intereses. } \\
\text { Bienes muebles y otros bienes y derechos de cualquier clase o naturaleza que } \\
\text { posean, cuyo valor supere los } 6.000 \text { euros. } \\
\text { Seguros de vida cuya indemnización supere la cifra de } 30.000 \text { euros. } \\
\text { Créditos, préstamos o deudas que integren el pasivo. }\end{array}$} \\
\hline \multirow[t]{4}{*}{ Presentación } & $\begin{array}{l}\text { Plazo: dos meses } \\
\text { desde la toma de } \\
\text { posesión }\end{array}$ & $\begin{array}{l}\text { Excepciones: } \\
\text { Las cuentas bancarias que sólo deberán declararse el } \\
\text { saldo a la fecha de toma de posesión y al momento del } \\
\text { cese. }\end{array}$ \\
\hline & & $\begin{array}{l}\text { Los valores mobiliarios, es decir, acciones, participacio- } \\
\text { nes en capital de sociedades, títulos de deuda pública, } \\
\text { fondos de inversión, certificados de depósitos y otros va- } \\
\text { lores mobiliarios, deberán declararse a fecha del nom- } \\
\text { bramiento y del cese; debiéndose actualizar a } 31 \text { de di- } \\
\text { ciembre de cada año. }\end{array}$ \\
\hline & \multicolumn{2}{|c|}{$\begin{array}{l}\text { Lugar: } \\
\text { Registro General de la Consejería de Hacienda y Administración Pública o } \\
\text { en cualquiera de los lugares previstos en el artículo } 38.4 \text { de la Ley } 30 / 1992 \text { o } \\
\text { telemática, a través del Registro Telemático único de la Administración de la } \\
\text { Junta de Andalucía mediante el portal www.andaluciajunta.es }\end{array}$} \\
\hline & \multicolumn{2}{|c|}{$\begin{array}{l}\text { Forma de presentación: } \\
\text { Modelo que se encuentra en el anexo del Decreto Andalucía 176/2005. }\end{array}$} \\
\hline Publicidad & \multicolumn{2}{|c|}{$\begin{array}{l}\text { En el Boletín Oficial de la Junta de Andalucía y en la página web de la Consejería } \\
\text { de Hacienda y Administración Pública. }\end{array}$} \\
\hline $\begin{array}{l}\text { Cons ecuen- } \\
\text { cias jurídicas } \\
\text { del incumpli- } \\
\text { miento del de- } \\
\text { ber }\end{array}$ & \multicolumn{2}{|c|}{$\begin{array}{l}\text { Infracción leve: } \\
\text { «La no declaración de actividades, bienes e intereses, en el correspondien- } \\
\text { te Registro, dentro de los plazos establecidos, cuando se subsane tras el re- } \\
\text { querimiento que se formule al efecto» (art. 15.3 Ley 3/2005). } \\
\text { Infracción grave: } \\
\text { «La no declaración de actividades, bienes e intereses, en el correspondien- } \\
\text { te Registro, tras el requerimiento para ello» [art. } 15.2 \text { c) Ley 3/2005]. }\end{array}$} \\
\hline
\end{tabular}




\section{La especialidad de las declaraciones tributarias}

$\mathrm{Al}$ margen de las declaraciones de actividades, bienes e intereses, la Ley Andalucía 3/2005, en su artículo 12.2, exige la presentación de la copia de la declaración del Impuesto sobre la Renta de las Personas Físicas y, en su caso del Impuesto de Patrimonio de cada ejercicio económico ${ }^{57}$, impuesto que, desde la Ley 4/2008, de 23 de diciembre, ya no se devenga aunque la Ley 19/1991 continúe vigente ${ }^{58}$.

Igualmente resulta significativa la previsión de algunas Comunidades Autónomas -también en la ley estatal- de la posibilidad del alto cargo de presentar la copia de las citadas declaraciones del cónyuge o persona con la que conviva en análoga relación de afectividad ${ }^{59}$. Para que se produzca esta posibilidad se requiere el consentimiento del cónyuge o persona vinculada, pues de otra manera se podrían ver afectados derechos de terceros y, por ello, en algunas normas se requiere expresamente el consentimiento, como es el caso de Galicia $^{60}$, exigiéndose incluso, como por ejemplo en La Rioja, que sea por escrito $^{61}$. Sin embargo, existe una excepción en el caso de Navarra que exige la presentación de esas declaraciones del cónyuge ${ }^{62}$.

${ }^{57}$ La presentación de las declaraciones tributarias son habituales en la legislación autonómica y así, por ejemplo, Cataluña - art. 12.b) Ley 13/2005-, Cantabria -art. 15.3 Ley 1/2008-, La Rioja - art. 8.3 Decreto 30/2004-, Madrid - art. 10.2 Ley 14/1995- Galicia -arts. 8.1 Ley 9/1996 y 2.4 Decreto 169/1995- Navarra - art. 12.3 Ley 19/1996- Castilla-La Macha -arts. 4.3 y 5 Ley 6/1994- exigen de igual modo la presentación de las citadas declaraciones aunque existen algunas particularidades como es el caso de Asturias sólo prevé patrimonio -art. 8.1Ley 4/1995-.

${ }^{58}$ Véase, sobre este particular, Meseguer Yedra (2007: 219 y ss).

${ }^{59}$ Como es el caso, entre otras, de los artículos 15.3 Ley de Cantabria 1/2008, de 2 de julio, reguladora de los Conflictos de Intereses de los miembros del Gobierno y de los altos cargos de la Administración de Cantabria y 10 Decreto La Rioja 30/2004. Asturias - art. 8.1 in fine Ley 4/1995- y Galicia - art. 8.1 in fine Ley 9/1996- solo se prevé la declaración de patrimonio del cónyuge o de persona vinculada por análoga relación de convivencia.

${ }^{60}$ Cfr. artículo 8.2 Ley 9/1996, de 18 de octubre, de incompatibilidades de los miembros de la Junta de Galicia y altos cargos de la administración autonómica.

${ }^{61}$ Cfr. artículo 10 Decreto La Rioja 30/2004.

${ }^{62}$ Cfr. artículo 12.3 Ley Foral 19/1996, de 4 de noviembre, de incompatibilidades de los miembros del Gobierno de Navarra y de los altos cargos de la Administración de la Comunidad Foral de Navarra. Esta previsión tiene un antecedente en el Real Decreto 1410/1995, de 4 de agosto, por el que se regulan los Registros de actividades y de bienes y derechos patrimoniales de los altos cargos que prevé que el carácter voluntario no lo será para los cónyuges de los altos cargos, que en virtud de una Ley específica, tuvieran la obligación de presentarla (art. 14.3). 
Esta declaración deberá presentarse junto con las declaraciones de actividades, bienes e intereses en el plazo previsto para las mismas y abordado supra, pero en los años sucesivos deberá presentarse durante el mes siguiente del plazo en que aquellas deban presentarse ante la Administración Tributaria (art. 12.2 Ley Andalucía 3/2005 y 11.2 Decreto Andalucía 176/2005).

La declaración del Impuesto de la Renta del Alto Cargo será depositada en el Registro de Actividades, Bienes e Intereses sin que pueda ser objeto de publicidad alguna como dispone el artículo 12.2 de la Ley Andalucía 3/2005 y el artículo 14.3 del Decreto Andalucía 176/2005.

\section{BIBLIOGRAFÍA}

FERNÁNDEZ RAMOS, S., El derecho de acceso a los documentos administrativos, Marcial Pons, Madrid, 1997.

GAMERO CASADO, E. y FERNÁNDEZ RAMOS, S., Manual básico de Derecho administrativo, Tecnos, Madrid, 2009.

GARCÍA MEXÍA, P., Los conflictos de intereses y la corrupción contemporánea, Aranzadi, 2001.

JIMÉNEZ BLANCO, A., «Estatuto de los miembros del Gobierno: deberes, derechos e incompatibilidades», en A.A. VV. (Coord. L. Parejo Alfonso), Estudios sobre el Gobierno, Universidad Carlos III y BOE, Madrid, 1996.

MESEGUER YEDRA, J., (2007), Régimen de conflictos de intereses e incompatibilidades de los miembros de los miembros del gobierno y altos cargos de la Administración, Bosch, Barcelona.

SARMIENTO MÉNDEZ, X. A., «As incompatibilidades dos membros da Xunta e demáis altos cargos», en Revista Xurídica de la Universidad de Santiago de Compostela, núm. 1 (1996). 